\title{
A esquerda, o Estado, a economia: considerações em torno à crise socioeconômica hodierna
}

Recebido: 12.02 .13

Aprovado: 22.08 .13
Leno Francisco Danner*

Resumo: Argumenta-se, neste artigo, que o debate em torno à resolução da crise econômica hodierna aguçou novamente o conflito entre uma posição social-democrata, marcada pela ênfase no Estado de bem-estar social em suas funções de intervenção econômica e de integração material, e uma posição neoliberal ou neoconservadora, marcada pela defesa de uma autorreferencialidade das relações de produção e, neste caso, pela afirmação de que a crise econômica é causada por mecanismos estranhos ao âmbito econômico (de origem política ou normativa) que violam esta sua lógica autorreferencial. Com isso, defende-se que, nestes primeiros anos do século XXI, a programática da esquerda, baseada na afirmação do Estado de bem-estar social, ganhou novo fôlego, escorada em amplo respaldo social, pondo em xeque princípios centrais do laissez-faire econômico e afirmando a diretiva política da evolução social.

Palavras-chave: crise econômica; social-democracia; neoliberalismo; Estado; política forte.

\section{Considerações iniciais}

A crise socioeconômica hodierna levou a uma reconsideração positiva do papel do Estado enquanto instância política diretiva da evolução social. Correlatamente, ela contribuiu para a retomada do clássico debate entre esquerda e direita, ou, mais especificamente, para o que aqui me interessa, entre social-democracia e neoliberalismo, debate esse que tinha na relação entre Estado de bem-estar social, democracia de massas e economia capitalista - suas especificidades, suas fronteiras e seus possíveis pontos de intersecção - a grande tônica. Por causa disso, a tematização do processo de modernização, em seu sentido amplo, econômico-social e político-cultural, adquire novamente centralidade em um momento no qual os critérios normativos de integração social e os instrumentos políticos de intervenção econômica, congregados no Estado de bem-estar social, estão sendo colocados na base de um conflito entre imperativos sistêmicos (poder de classe, manutenção do status quo e dinheiro) e necessidades sociais (interesses universalizáveis) no que tange às reformas institucionais a serem tomadas para a resolução da crise, por parte dos grupos políticos que disputam hegemonia em termos de realpolitik. ${ }^{1}$ Por um lado, os mecanismos estatais de intervenção econômica e de compensação social são afirmados pela esquerda teórico-política de uma maneira geral e pela social-democracia em particular, respaldadas por um amplo consenso social acerca da premência de prote-

\author{
* Doutor em \\ filosofia (PUC-RS). \\ Professor de filosofia \\ e de sociologia \\ na Fundação \\ Universidade Federal \\ de Rondônia (Unir). \\ <leno_danner@ \\ yahoo.com.br>. \\ 1. Utilizo o termo \\ realpolitik para \\ significar a dinâmica \\ política cotidiana, \\ em seu viés \\ administrativo- \\ partidário, \\ envolvendo, por \\ conseguinte, as \\ lutas partidárias \\ em busca de \\ hegemonia política, \\ a administração \\ estatal e sua relação \\ com o poder \\ econômico-social \\ em suas variadas \\ formas. É, sob \\ muitos aspectos, a \\ política analisada \\ por Maquiavel e \\ por Marx. Quanto \\ aos conceitos \\ de imperativos \\ sistêmicos e \\ necessidades \\ sociais ou interesses \\ universalizáveis \\ (generalizáveis), eu \\ os tomo emprestado \\ de Habermas (2001).
}


ger-se o mundo da vida frente à expansão desenfreada do processo de acumulação econômica (proteção que se dá a partir do fortalecimento do Estado de bem-estar interventor e compensatório); por outro lado, as posições teórico-políticas neoconservadoras ainda ecoam com considerável força a importância de proteger-se a especificidade e a autorreferencialidade das relações de produção frente ao poder político interventor e à radicalização dos critérios normativos da democracia político-cultural e dos direitos sociais de cidadania, próprios das sociedades democráticas contemporâneas, que a rigor enquadrariam essas mesmas relações de produção. Este conflito está novamente acentuando-se, na realpolitik hodierna.

Defenderei, ao longo do texto, com base nisso, três argumentos. O primeiro consiste em que essa disputa entre imperativos sistêmicos e necessidades sociais remete-se diretamente ao combate entre uma posição neoconservadora ou neoliberal, defensora de uma separação estrita entre os âmbitos econômico, político e social, a partir da ênfase na autorreferencialidade da economia, que instrumentalizaria o político e enquadraria o social, e uma posição social-democrata, de esquerda, para quem o político, fundado normativamente, deveria regular o econômico com vistas à promoção do social, já que o econômico está inserido, radicado neste âmbito social, e não o contrário (o econômico estaria radicado no social inclusive no sentido de depender dos impulsos normativos e motivacionais gerados neste).

O segundo argumento consiste em que o Estado de bem-estar social, em suas funções de regulação econômica e de integração material, permitiria a superação das fraturas da modernidade liberal, caracterizada pela separação e pela afirmação de uma autorreferencialidade dos âmbitos econômico, político e social, que, dotados de uma lógica imanente própria, seriam solapados em suas especificidades e, em última instância, travados sempre que essas lógicas imanentes e autorreferenciais fossem violadas por outras lógicas. Com isso, o econômico, no caso do liberalismo clássico, abarcaria o social, retirando-lhe a normatividade, ao mesmo tempo em que instrumentalizaria o político, transformando-o em instituição de legitimação e de reprodução das relações de produção, que, nessa sua função, adequaria o social ao econômico. Ora, o ataque ao Estado de bem-estar social e ao conteúdo normativo dos direitos sociais de cidadania, desfechado pelo neoliberalismo desde meados da década de 1970 (ver Katz, 1989; Habermas, 1997), retomou essa compreensão liberal do processo de modernização, contra a social-democracia.

O terceiro argumento, por fim, enfatiza, de um lado, que a posição social-democrata, no que tange ao projeto de Estado de bem-estar social, busca a articulação entre os âmbitos econômico, político e social, por meio da afirmação do social como horizonte normativo que, devido à sua amplitude, englobaria as relações de produção e orientaria o poder político, normativamente definido, a regular essas mesmas relações de 
produção, canalizando-as também para a satisfação de necessidades sociais. Nesse sentido, o processo de modernização econômico-social, para uma posição social-democrata, deve ser enquadrado pela normatividade consolidada em termos de modernização cultural, isto é, a partir de interesses generalizáveis, que apontariam para a extensão dos processos democráticos para todas as esferas da sociedade, permitindo uma imbricação profunda entre as esferas econômica, política e social - e, com isso, contrapondo-se radicalmente ao neoliberalismo ou neoconservadorismo. Assim, de outro lado, o Estado de bem-estar social seria colocado como a instância na qual as fraturas da modernidade liberal seriam sanadas, exatamente pela afirmação da normatividade do social enquanto enquadrando o econômico e definindo o sentido do poder político, que é colocado como a instância diretiva por excelência da evolução social.

Ora, a crise econômico-social atual e as possíveis soluções para ela estão reativando o debate sobre a modernização e, com isso, a contraposição entre uma postura neoliberal ou neoconservadora e uma postura social-democrata particularmente no que diz respeito à ligação - ou à recusa dela - entre as esferas econômica, política e social, bem como no que se refere ao fato de se é o econômico que, por causa de sua autorreferencialidade, enquadra o social e orienta o poder político, ou se, ao contrário, é o social, normativamente definido, que enquadra o econômico e orienta a estruturação e a atuação do poder político congregado no Estado. Desse modo, o debate entre esquerda e direita relativo ao entendimento do processo de modernização ganha novo fôlego, direcionando-se à própria compreensão do Estado de bem-estar social, de seus fundamentos, de seu tamanho, de seus instrumentos e de suas funções - um combate, tanto em termos teóricos quanto em termos de realpolitik, que é central para definir, por um longo tempo, o modo como a crise socioeconômica será tematizada e resolvida.

Gostaria de ressaltar que, para fins de argumentação teórica, separo os âmbitos social, político e econômico (na prática evidentemente inseparáveis), como forma de esclarecer de modo mais consistente as especificidades do neoliberalismo e da social-democracia que me parecem importantes para o entendimento do tipo modelar de relação que, por causa de tais especificidades, orienta cada posição teórico-política comentada (são, de todo modo, conceitos bem gerais, aos quais peço a gentileza de aceite do leitor). O social diz respeito ao horizonte da vida cotidiana, aos interesses dos diferentes indivíduos e grupos sociais em sua vida em comunidade - a vida boa de cada indivíduo e grupo social. O econômico diz respeito diretamente às relações de produção no mercado (o mercado ou o econômico, aqui, é um horizonte mais restrito do que o social, e este abarca àquele). O político é o meio a partir do qual as reivindicações ligadas ao social e as necessidades de reprodução do econômico, ao entrarem em relação (e, no caso do capitalismo, em uma relação bastante contraditória) são intermediadas. Nesse aspecto, o social carrega pretensões de validade 
que podem ou não ser universalizáveis - o social é, ao longo do texto, um horizonte normativo, ético. O econômico é um horizonte instrumental, ligado à dinâmica do processo de produção e de distribuição da riqueza social. E o político é o instrumento a partir do qual reivindicações normativas (social) ou instrumentais (econômico) são realizadas, dependendo das lutas políticas que são travadas e da hegemonia das forças políticas em combate, em termos de realpolitik. Com base nisso, defenderei que o neoliberalismo, recuperando o liberalismo econômico clássico, afirma não a dependência recíproca entre os âmbitos, mas sua separação estrita, no sentido de que a lógica de cada um deles Ihe é específica, não podendo ser violada pela lógica de outro. O econômico, por causa disso, possuiria uma lógica própria, autorreferencial (o processo de produção e de distribuição da riqueza como fim em si mesmo e dependente do laissez-faire), que não poderia ser subsumida à normatividade do social e ao sistema político normativamente orientado. Para o neoliberalismo, portanto, as lutas sociopolíticas em torno à política, ao visarem a orientação normativa da esfera econômica, violam a lógica autorreferencial do capital, emperrando-a. Daqui também surge a consequência de que as pretensões sociais, em termos de direitos sociais de cidadania, perdem legitimidade, não podendo adentrar nem da esfera da produção e nem, em poderosa medida, no horizonte das administrações estatais, transformando a política em um instrumento de legitimação da lógica autorreferencial da economia, que passa a não aceitar argumentos normativos como forma de orientação de sua dinâmica instrumental. Já a social-democracia, desde os tempos de Bernstein, parte da afirmação de que o econômico está ligado ao - e dependente do - social, exatamente porque é do horizonte normativo constituído por este último que partem todos os impulsos necessários para a viabilidade do econômico. Nesse sentido, ao poder político caberia a árdua tarefa de refreamento e de sensibilização do poder econômico a partir da afirmação dos direitos sociais de cidadania e do fortalecimento do Estado de bem-estar social em suas funções de regulação econômica e de integração material, levando ao fortalecimento da sociedade civil e dos movimentos sociais e de trabalhadores ali originados, que poderiam oferecer contraposição política às classes capitalistas.

\section{A retomada de um confronto: política forte versus laissez-faire}

Com efeito, a atual crise socioeconômica aguçou novamente um tema que foi caro ao neoliberalismo, em sua retomada do liberalismo clássico contra a social-democracia, a saber: a defesa de que há uma lógica imanente às relações de produção, que é autorreferencial e que, uma vez invadida por princípios externos, é solapada em sua especificidade, travando ferreamente. No mesmo sentido, portanto, a crise, segundo uma posição neoconservadora, advém do fato de que mecanismos alienígenas teriam sido utilizados como critérios reguladores do âmbito econômico, embora não fizes- 
sem parte deste mesmo âmbito econômico. Por causa disso, a lógica do processo de produção do capital foi abalada estruturalmente.

A defesa da autorreferencialidade da esfera econômica é fundamental para compreender-se o sentido do neoconservadorismo. Ela é caudatária da compreensão liberal clássica em relação ao fenômeno da modernização, que entendia o processo de constituição das sociedades modernas a partir de uma dinâmica determinada por três momentos: $a$. indivíduos formam uma organização social, política e jurídica, cujo objetivo é proteger-Ihes e a sua propriedade (no sentido lockeano); $b$. a propriedade (ainda ao estilo lockeano) faz parte de uma esfera privada, determinada pelo trabalho e pela produção (também entendidos como privados); e, como consequência, c. essa organização social, política e jurídica tem no Estado sua instância legitimadora, que, a partir do reconhecimento das relações de produção enquanto fazendo parte da esfera privada, possui por tarefa a proteção destas relações de produção em sua natureza de propriedade privada. Note-se, em relação a isso, que tais relações de produção servem de substrato para definir-se o sentido do poder político, na medida em que elas enquadram, de uma maneira geral, isso que entende-se por social: o social é percebido, basicamente, enquanto esfera abarcada pelo bourgeois e sintetizada nele, ou seja, pelo indivíduo produtivo e pelas relações de produção que são geradas a partir da relação dos burgueses entre si, naquele âmbito privado constituído pela economia e cujo resultado final é a propriedade, que é determinada fundamentalmente pela meritocracia do trabalho (ver Macpherson, 1972; 1991). A relação social modelar, em Locke, é exatamente esta vida econômica representada pelo burguês, que abarca todos aqueles que vivem do trabalho, seja - agora utilizando uma terminologia marxiana - o capitalista, seja o proletário (para Locke ambos são apenas trabalhadores). $A$ relação econômica calcada no burguês, por conseguinte, é generalizada como o caso exemplar para pensar-se a organização sociopolítica de um modo mais geral. Todas as demais relações e a estruturação das instituições são dependentes dela e determinadas pela igualdade dos trabalhadores entre si, que afirmaria a meritocracia do trabalho como a forma por excelência de distribuição da riqueza, do poder, e mesmo de definição do status quo.

Por causa disso, tem-se a institucionalização de um poder político que, como bem chamou a atenção Marx, reproduz relações de classe exatamente por estar ancorado na compreensão da propriedade (em outros termos: das relações de produção) enquanto pertencente a uma esfera privada, determinada única e exclusivamente pelo trabalho de cada indivíduo, não existindo qualquer poder de classe ou alguma estrutura sociopolítica que pudesse minar a distribuição do produto social e a paridade entre os produtores (ver Marx, 2006; Marx \& Engels, 2008). Aqui, apareceria mesmo o sentido específico do laissez-faire, já que as relações de produção seriam marcadas pela equidade no ponto de partida, de modo que o resultado final, em não existindo 
nenhuma macroestrutura sociopolítica determinadora do processo distributivo, seria justo para todos e corresponderia ao trabalho que cada indivíduo realizou com a intenção de obter a maximização de seu bem-estar pessoal - cada indivíduo é o único responsável pela sua situação e por seu status social (isto é, meritocracia do trabalho).

Em uma ordem econômica na qual não há nenhum poder arbitrário ou macroestrutural a determinar seus resultados, mas sim uma mão invisível caracterizada como uma espécie de ausência de poder estrutural, como um não poder estrutural, o laissez-faire transforma-se na lógica definidora da dinâmica e do sentido das relações de produção - uma lógica que aponta diretamente para a autorreferencialidade da esfera econômica, percebida como privada, local neutro no que tange às influências do poder estrutural. Ela necessitaria, basicamente, ser complementada por um poder político instrumental, marcado pela realização da justiça comutativa, isto é, pela proteção da propriedade e pela legalização dos pactos. Com isso, instaura-se, na compreensão liberal da modernidade, uma dinâmica entre as esferas econômica, política e social que é determinada pela centralidade e pelo caráter privado das relações de produção, que abarcariam o social (entendido também como esfera privada, pertencente ao conjunto das relações de produção) e que imprimiriam ao poder político uma tônica ligada ao laissez-faire e caracterizada pelo fato de que ele necessita basicamente garantir os aspectos técnicos (justiça contratual e comutativa, como se disse acima) que viabilizam exatamente esse laissez-faire - tem-se uma espécie de Estado mínimo legitimando e reproduzindo as relações de produção (ver Habermas, 1994; 1999).

Ora, é muito interessante que o neoliberalismo, a partir da década de 1970 (na figura de Hayek, por exemplo), enfatize, em particular, as ideias de mercado como ordem espontânea e de evolução espontânea da sociedade, em uma clara reafirmação do liberalismo clássico e explicitando, como consequência, a ideia de que a sociedade como macroestrutura ou totalidade constituída de estruturas institucionais simplesmente não existe. Pois que a ideia de uma evolução espontânea da sociedade a partir da dinâmica interna das relações de produção (concebidas enquanto dotadas de uma lógica autorreferencial, antiestrutural e apolítica - mercado como ordem espontânea) significa que a pretensão da teoria social de identificar déficits estruturais, mediados, legitimados, determinados institucionalmente, no que tange às relações produtivas e políticas entre indivíduos e grupos - déficits esses que, por sua vez, imprimiriam a desigualdade como o princípio e como o fim daquelas relações -, é negada no momento em que, como quer Hayek, essas estruturas institucionais não existem. Ora, também é a partir da afirmação da existência de estruturas institucionais influenciadas pelo poder de classe que os teóricos sociais (pense-se, por exemplo, nas várias posições filosófico-sociológicas escoradas nas investigações de Marx ou suas herdeiras, incluindo-se, aqui, hodiernamente, as sucessivas gerações da Escola de Frankfurt) podem analisar empírica e normativamente esses mesmos déficits, condenando-os e, por 
outro lado, sugerindo reformas com vistas a sanar os problemas sociopolíticos daí decorrentes. Mas é importante ter-se em mente exatamente isso: que é por meio do reconhecimento da sociedade enquanto totalidade, constituída não apenas por indivíduos, senão que também por grupos sociais e por instituições, que define-se o sentido da teoria social, conferindo-lhe objetividade analítica e respaldo normativo. Em última instância, dessa afirmação depende toda a possibilidade da teoria social, ainda que esta tenha apenas um cunho positivista, o que nem sempre é o caso.

E, neste aspecto, é bem clara e central, no neoliberalismo e como forma de definir seu sentido, a defesa de que a sociedade, no fim das contas, é constituída por uma multiplicidade amorfa de indivíduos voltados, cada um deles, à persecução de seu bem-estar pessoal. É daqui que se instaura uma dinâmica associativa entre eles, que, ao buscarem por meio dos outros a realização de seus próprios interesses, também oferecem a eles os seus talentos. Nesse sentido, o processo evolutivo foi - e é - definido a partir da seleção de regras de sociabilidade que melhor representassem essa espontaneidade das atividades produtivas, já que a associação desses mesmos indivíduos entre si com vistas ao proveito pessoal deu-se - e dá-se -, fundamentalmente, com base nas atividades produtivas. Estas definem o sentido da sociabilidade e, como consequência, o próprio modo como o poder político será orientado.

Um dos pontos fundamentais no que tange à compreensão do poder político, por conseguinte, consiste na lógica imanente que preside as atividades produtivas e as relações de produção, lógica essa caracterizada como espontânea e determinada pela interação dos indivíduos entre si, que é orientada basicamente pelos talentos de cada um deles. Quer dizer, o processo produtivo e sua distribuição, na ideia de mercado como ordem espontânea, são configurados por meio do desenvolvimento das habilidades de cada indivíduo, de modo que o resultado final advém exatamente da quantidade e da qualidade dos talentos de cada indivíduo, o que implica em que um resultado final desigual em termos de distribuição da riqueza produzida não é injusto. Com isso, o conceito de justiça social é uma miragem, da mesma forma como a ideia de um Estado interventor e compensatório não possui fundamento, já que ambas dependem tanto da existência de estruturas institucionais que influenciam as relações de produção, determinando seu resultado final, quanto de que essas mesmas relações de produção sejam perpassadas por interesses generalizáveis sob a forma de reivindicações normativas, o que não é o caso, posto que as relações de produção são influenciadas pura e simplesmente pelo desenvolvimento maior ou menor dos talentos individuais (ver Hayek, 1985; 1987; 1988). A sociedade, objetivamente falando, não existe, e sim apenas indivíduos, como diria Thatcher, representando bem essa posição de Hayek (ver Harvey, 2008; Habermas, 2000). Assim, na medida em que a sociedade enquanto totalidade não existe, bem como no momento em que a evolução acontece a partir das interações anônimas e espontâneas realizadas em ter- 
mos de mercado, uma política diretiva da evolução social, normativamente fundada, é invalidada, posto que não é por meio da política que essa mesma evolução social acontece, e sim por meio do mercado enquanto ordem espontânea. Faz sentido, com isso, a recusa enfática, nas posições neoliberais, da política enquanto instância central da evolução social, o que equivale, correlatamente, à contraposição ao modelo representado pelo Estado de bem-estar social.

Ora, uma das posições teórico-políticas referente à compreensão da crise socioeconômica hodierna escora-se diretamente na postura neoliberal, na medida em que compreende a crise como sendo originada pelo solapamento da lógica inerente às relações de produção, seja por causa do intervencionismo político do Estado no que tange à produção da riqueza, seja por causa da amplitude e do sentido normativo dos direitos sociais de cidadania, que generalizam as medidas interventoras e compensatórias a serem tomadas pelo Estado de bem-estar social, travando a submissão do trabalho ao capital e, por conseguinte, aliviando as classes trabalhadoras da pressão por inclusão no mercado de trabalho. E, ainda para esta posição, tanto o intervencionismo político quanto a justiça distributiva escorar-se-iam na pressuposição de que a produção e a distribuição da riqueza são determinadas por estruturas objetivas para além dos indivíduos e de seus talentos, de modo que far-se-ia necessário a instauração de um poder estatal corretivo e compensatório dessas injustiças que são causadas aos indivíduos. Isso implica em que a lógica da política (regulação, direção) e a lógica do social (normatividade) adentrem na esfera econômica e violem, aqui, a lógica da produção do capital (laissez-faire, meritocracia do trabalho).

\section{A social-democracia e o sentido da crise socioeconômica hodierna}

E essa posição neoconservadora ataca diretamente a social-democracia, propugnadora do projeto de Estado de bem-estar social, que é a outra proposta teórico-política central para compreender-se a crise socioeconômica hodierna. A social-democracia europeia sempre definiu-se, de uma maneira geral, pelo objetivo de conciliação entre capital e trabalho, a partir da promoção do mundo da vida frente aos imperativos sistêmicos, baseada na centralidade do Estado de bem-estar social em suas funções interventoras e compensatórias (ver Abendroth, 1977; Rosanvallon, 1998; Hook, 1999; Kolakowski, 1999; Harrington, 1999; Habermas, 2009; Streeck, 2012). Nesse caso, a questão-chave consistiria em adequar-se o processo de produção capitalista às necessidades de justiça social e democracia política. De fato, para esta posição teórico-política, a íntima imbricação entre direitos individuais fundamentais, direitos políticos e direitos sociais, própria das democracias contemporâneas, enquanto síntese das revoluções burguesas modernas e dos movimentos proletário-socialistas, constitui o cerne de uma programática que aponta exatamente para a necessidade correlata de 
promoção e de controle da esfera econômica com a realização de um amplo leque de direitos sociais de cidadania e a viabilidade de processos de democracia política ampliada. Aqui, o poder político estaria ancorado na normatividade adveniente do mundo da vida, para utilizar um termo habermasiano, e enquadraria as relações de produção exatamente com o objetivo de salvaguardá-lo frente ao processo de acumulação.

Para a social-democracia, o sentido da crise consistiria em que a lógica da produção capitalista, voltada à produção de mais-valia (valor de troca), defronta-se, de tempos em tempos, com crises cíclicas, cada vez mais acentuadas na fase do capitalismo monopolista, na qual as grandes corporações transnacionais orientam os mercados de produção e de trabalho, de um modo tal que os princípios do liberalismo clássico (/aissez-faire, mão invisível) são implodidos pelo poder estrutural reunido monopolisticamente. De um lado, portanto, em uma economia monopólica, não apenas a produção está integrada em cadeias cada vez mais internacionalizadas, senão que, em certos setores estratégicos, as pequenas empresas entram em processo de falência, frente aos grandes conglomerados - na verdade, tais conglomerados passam a orientar a dinâmica dos setores estratégicos e, de quebra, a própria postura estatal frente às necessidades de valorização do capital. Essa tendência do capitalismo tardio, ${ }^{2}$ de uma monopolização cada vez mais acentuada do setor produtivo-financeiro, bem como de sua progressiva internacionalização, que levou à desregulação dos mercados e do capital a partir da afirmação de um Estado mais enxuto e orientado pelo laissez-faire (em termos de neoliberalismo, nas décadas de 1980 e de 1990), são o grande pilar da crise, haja vista o processo de falência apontado acima como resultado da própria dinâmica monopolista. Elas implicam, inclusive, na pressão frente aos Estados nacionais no que tange às suas próprias posturas intervencionistas em relação ao capital e compensatórias em relação ao trabalho - desfavoráveis em ambos os aspectos (ver Chesnais, 2006; Krugman, 2009).

A monopolização e a internacionalização da economia causam, de outro lado, uma crise da sociedade do trabalho. Com efeito, a internacionalização da produção permite que o preço da mão de obra seja determinado a partir de critérios que minam a organização sindical e o poder de pressão das classes trabalhadoras, na medida em que a produção, configurada globalmente, passa a ser realizada naqueles lugares nos quais a valorização do trabalho é menor e que têm uma organização trabalhadora e sindical mais fraca. Isso, por sua vez, causa uma pressão salarial nas sociedades desenvolvidas, nas quais o preço da mão de obra é mais alto e as classes trabalhadoras mais organizadas, levando a uma readequação do trabalho, bem como a demissões em massa. O desemprego estrutural, uma realidade cada vez mais grave e consolidada das sociedades desenvolvidas, atinge, em muitos casos, mais de $10 \%$ da população ativa, chegando mesmo a $20 \%$ dessa mesma população produtiva. E ele parece ser uma tendência como que inerente ao próprio crescimento econômico que, por exem-
2. Utilizo este conceito conforme a apropriação feita dele por Habermas, a saber: economia monopólica e transnacionalizada, crescimento do capital especulativo e aumento das atividades interventoras e compensatórias do Estado. Sobre isso, ver: Habermas, 1994. 
plo, na década de 1990, marcou a economia europeia de um modo geral (jobless growth) - tendência essa que, sob muitos aspectos, foi acirrada neste momento atual, no qual, se por um lado a crise da economia produtiva é um fato, por outro o crescimento do capital especulativo representa uma das grandes especificidades. Ora, a crise socioeconômica hodierna é marcada por estes dois pontos: $a$. uma economia monopólica que volta-se contra mecanismos estatais regulatórios, marcada pelo decréscimo dos padrões de acumulação, aliada em muitos casos com o predomínio do capital financeiro-especulativo, causando $b$. o crescimento do desemprego estrutural (ver: Antunes, 2005; Kurz, 2005; Gorz, 2005). E as duas principais saídas mais salientadas para a mesma, conforme percebo em termos de realpolitik atual, são: retomada do laissez-faire, disfarçado de política de austeridade; reafirmação de uma política forte, congregada em um Estado interventor e compensatório.

Neste ponto, a social-democracia responde à crise com o fortalecimento das atividades regulatórias e compensatórias, ou, pelo menos, não endossa totalmente aquela agenda neoliberal de desregulação e de redução dos benefícios sociais que marcou as décadas de 1980 e de 1990, e que hoje, sob muitos aspectos, parece estar rediviva enquanto alternativa à atual crise. Para esta posição, a autorreferencialidade da esfera econômica frente ao político e ao social é fictícia, devendo ser contrabalançada e equilibrada por meio da afirmação do social frente ao econômico, através do político. Esta, como acredito, é a ideia mestra do edifício teórico-político social-democrata, a saber: a centralidade normativa do social, que englobaria o econômico e fundamentaria um poder político direcionado ao enquadramento das relações de produção com vistas à promoção do social. Não é mero acaso, portanto, que Hayek tenha ironicamente dedicado sua obra $O$ caminho de servidão aos partidos social-democratas e trabalhistas da Europa ocidental, em meados da década de 1940, período no qual começava a reconstrução daquelas sociedades (fundada no reformismo social-democrata e trabalhista). O referido pensador tinha por alvo tanto o intervencionismo (planejamento central da economia, a partir do Estado de bem-estar social) quanto o crescimento dos direitos sociais de cidadania e das políticas redistributivas e compensatórias por eles exigidas - para Hayek, isso era socialismo burocrático pura e simplesmente, que implicaria no aumento dos controles estatais em relação ao mercado de uma maneira específica.

Já na década de 1970 em diante, quando a teoria neoliberal passou a ganhar cada vez mais notoriedade, polarizou-se de um modo claro a disputa entre concepções políticas que, de um lado, no caso do próprio neoliberalismo, atacavam o Estado de bem-estar social (em suas tarefas interventoras e compensatórias) com base no argumento de uma lógica específica ao âmbito econômico, violada em sua autorreferencialidade e em sua especificidade por princípios político-normativos, e que, de outro, no caso da social-democracia, propunham o enfrentamento da crise por meio do fortalecimento 
do Estado e de suas atividades de promoção do crescimento, de controle dos fluxos de capital, de orientação da produção e de inclusão material dos necessitados.

Esse confronto é sintomático para perceber-se muito da orientação dada, em termos teóricos e de realpolitik, à compreensão das crises socioeconômicas das três últimas décadas do século XX, na medida em que a relação entre Estado e mercado deu o mote das reflexões em torno ao sentido dos problemas enfrentados. De fato, nesse confronto, a posição neoliberal assumiu uma postura favorável ao restabelecimento da lógica autorreferencial do processo produtivo, processo produtivo esse que estaria, a partir de fins do século XX, integrado mundialmente, exigindo, por isso mesmo, flexibilidade e adaptação, por parte dos Estados nacionais, às exigências de mobilidade do capital e do trabalho, em particular no que diz respeito à reformulação de suas (dos Estados) tarefas interventoras, que deveriam ser reduzidas, possibilitando uma retomada do laissez-faire econômico. O Estado de bem-estar social, além disso, deveria restringir sua atividade compensatória ao absolutamente necessário e centrar-se na preparação de capital humano para esse mercado globalizado, diminuindo, assim, o endividamento público crescente. Em tudo isso, na compreensão neoliberal, a agenda política consistia em reafirmar a centralidade das relações de produção para a evolução social, que deveriam receber a devida prerrogativa diante de exigências político-normativas que não se coadunariam com a lógica autorreferencial da produção.

Entretanto, não é possível pura e simplesmente lançar-se fora o Estado interventor e compensatório, que sobreviveu muito bem, na Europa de uma maneira geral, não obstante a hegemonia neoliberal, em vários países do continente, nas décadas de 1980 e de 1990, quando propagandeou-se uma espécie de cruzada contra o Estado de bem-estar social, nas suas funções acima comentadas (ver: Kuhnle, 2007; Ferreira, 2007; Manow, 2007; Merriem, 2007). Visto a partir de um prisma filosófico-sociológico, ele tem por função exatamente superar aquela visão liberal do processo de modernização, no sentido de que, em sua estrutura político-administrativa, a democracia de massas adquire primazia. Como penso, há uma enfática afirmação de que, nas democracias de massa contemporâneas, estruturadas a partir do Estado social e democrático de direito, o âmbito social, normativamente fundado (e entendido, na linguagem habermasiana, como mundo da vida), oferece o substrato no que tange à orientação social do poder político, que deve domesticar as relações de produção, garantindo que padrões de justiça sociopolítica sejam realizados universalmente a todos os cidadãos.

Portanto, o Estado de bem-estar social está respaldado em um amplo consenso democrático ligado à percepção de que o conflito entre imperativos sistêmicos e necessidades sociais é real e potencialmente explosivo, de modo que ele (o Estado) é colo- 
cado como a instância política diretiva da evolução social, canalizando a produção da riqueza social para a garantia de padrões mínimos de integração material para todos. No caso do neoliberalismo, a evolução social é dinamizada pelo mercado enquanto ordem espontânea, sendo ela mesma uma espécie de consequência espontânea das interações entre indivíduos produtivos em termos de mercado (que, por sua vez, dinamizaria toda a evolução social). Aqui, um Estado diretivo, como acreditava Hayek, não faz o mínimo sentido, porque violaria essa lógica que perpassa as relações de produção. Mas este não é o caso para a posição social-democrata, como venho afirmando. Para esta posição teórico-política, a ideia de um Estado diretivo da evolução social, orientando o âmbito econômico a partir dos interesses generalizáveis socialmente fundados, é fundamental no que diz respeito à própria viabilidade de uma evolução social ancorada em princípios democráticos - uma evolução social passível de ser dirigida, ainda que em aspectos pontuais, politicamente.

Como o reconheceu o próprio Habermas, a esfera pública da social-democracia é afirmada como complemento do poder político-administrativo exatamente porque reconhece-se tanto a ancoragem do poder no mundo da vida quanto, no mesmo sentido, sua permanente necessidade de legitimação frente aos interesses generalizáveis lançados deste rumo àquele (ver Habermas, 1984). Por causa disso, o Estado de bem-estar social é caudatário de uma esfera pública politizada, que afirma a premência da diretiva política da evolução social, realizada por meio dele. Ou seja, a social-democracia está ligada umbilicalmente à consolidação de uma esfera pública democrática, normativamente definida e inclusiva, na qual o processo de interação entre o poder político-administrativo e os movimentos sociais e as iniciativas cidadãs advenientes da sociedade civil adquire primazia frente à suposta lógica autorreferencial dos imperativos sistêmicos. O poder político-administrativo é percebido como estando fundado em normatividade, como sendo dependente desta normatividade que lhe é projetada da sociedade civil e que o coloca enquanto instância diretiva por excelência da evolução social e, neste caso, como devendo regular adequadamente as relações de produção, perpassadas pelo poder de classe. Mas é exatamente pela existência de relações de classe, de poder estrutural incrustado nas relações de produção e reproduzido por elas, que a ideia de democracia somente é viável a partir da instituição de um Estado que assuma efetivamente a responsabilidade de, enquanto núcleo político diretivo da evolução social, enquadrar a esfera econômica com base nos interesses sociais normativamente definidos.

Essa é a questão-chave no que tange à compreensão do Estado de bem-estar social, em termos de posição teórico-política social-democrata, e é ela que, em relação à crise econômica hodierna e à solução neoconservadora de uma política de austeridade, leva novamente a um papel de protagonismo da esquerda. Se, nesse sentido, as décadas de 1980 e de 1990 foram marcadas pela hegemonia neoliberal e pela cri- 
se da esquerda em grande parte das sociedades do Ocidente (para não dizer-se mais além), estes primeiros anos do século XXI apontam claramente para a renovação da esquerda e para a retomada de sua programática. A esquerda, conforme penso, saiu fortalecida do século XX, entrando no século XXI escorada em um amplo respaldo social acerca dessa sua programática calcada no Estado de bem-estar social.

\section{Considerações finais:}

\section{contornos atuais do confronto teórico-político entre direita e esquerda}

Habermas definiu, no caso da Europa ocidental, a posição teórico-política social-democrata, em seu projeto de Estado de bem-estar social, como o único caminho que teria restado à esquerda - na verdade, como representando uma genuína posição de esquerda, que teria na continuidade reflexiva do projeto de Estado de bem-estar social seu núcleo programático (ver Habermas, 1991). Acredito, em relação a isso, que alguns pontos da social-democracia, referidos por Habermas, são esclarecedores para pensar-se a crise socioeconômica atual e, nesse contexto, o papel da esquerda e a reconsideração positiva do Estado de bem-estar social.

Em primeiro lugar, Habermas alerta para a necessidade de não se confundir a esquerda da Europa ocidental com o projeto representado pelo socialismo real. Para aquela, de um modo geral, o modelo do socialismo real sempre foi percebido como uma deturpação de um projeto de esquerda, como uma negação daquele ideal que, desde Marx, teria inspirado os movimentos de trabalhadores, os partidos social-democratas e as lutas sociais em torno ao político: isto é, a progressiva democratização do poder em todas as esferas da sociedade. Nesse sentido, em segundo lugar, é importante perceber-se que o foco da esquerda da Europa ocidental teria sido direcionado à domesticação social do capitalismo nos marcos de uma democracia de massas, cujo conteúdo político seria representado pelo Estado de bem-estar social. Ora, aqui está o verdadeiro significado do projeto dessa mesma esquerda da Europa ocidental - que, em certo momento, Habermas chegou a considerar uma espécie de modelo para a esquerda de outros contextos (ver Habermas, 1997) -, a saber: o projeto de Estado de bem-estar social, marcado pela imbricação entre democracia política, justiça social e inclusão cultural. Para o referido autor, este projeto constituído pelo Estado de bem-estar social deveria ser retomado, defendido com unhas e dentes em um momento no qual tanto a hegemonia de posições neoconservadoras (nas décadas de 1980 e de 1990) quanto a progressiva desestruturação desse mesmo Estado de bem-estar social estavam em processo acelerado.

Desde meados da década de 1990, como penso, a perda de força das posições neoliberais, a crise econômica crescente e a consolidação do desemprego estrutural esta- 
riam apontando novamente para a importância das funções enfeixadas pelo Estado de bem-estar social. Com isso, a esquerda e sua programática estariam adquirindo novo protagonismo em um momento no qual novamente duas opções colocam-se no cenário político no que tange à resolução da crise socioeconômica hodierna: de um lado, posições conservadoras enfatizam a austeridade fiscal como condição da retomada do crescimento, atacando as tarefas de intervenção econômica e de integração material enfeixadas pelo Estado de bem-estar social; de outro lado, posições mais próximas à esquerda defendem um papel ativo do Estado em termos de fomento do crescimento econômico, de regulação do capital e de integração material. É claro, conforme penso, que não se pode confundir tais opções com uma questão meramente técnica, porque não é apenas isso que está em jogo: tais medidas administrativas fazem parte de uma compreensão mais profunda sobre o significado do político, sobre a relação, comentada ao longo deste texto, entre as esferas econômica, política e social.

O que efetivamente está em questão - e isso de um modo renovado - é o tipo de relação que deve ser estabelecida entre tais esferas. De um lado, as posições neoconservadoras insistem no laissez-faire como o programa político por excelência, já que partem da recusa de que as instituições (e, em particular, as instituições econômicas) possam ser perpassadas por déficits estruturais, sendo influenciadas pelo poder de classe. Elas ainda permanecem presas à concepção de uma autorreferencialidade das esferas econômica, política e social, que implica em que o âmbito econômico seja afirmado como sendo dotado de uma lógica autorreferencial (laissez-faire), não normativa, apolítica e antiestrutural, conforme dito acima. Para estas posições neoconservadoras, a dinâmica social reduz-se basicamente aos movimentos do bourgeois, do indivíduo produtivo e competitivo, que necessita de liberdade de condições para poder, como consequência, dar sua melhor contribuição a isso que ficticiamente chama-se sociedade, por meio do processo de produção e de acumulação do capital, e tendo como base a meritocracia do trabalho como o fundamento do status quo. De outro lado, posições de esquerda - social-democratas e trabalhistas - insistem na defesa de que as relações de produção não podem ser compreendidas apenas com base no laissez-faire e na dinâmica que a partir dele entabula esse mesmo bourgeois. Para estas, o equilíbrio do processo evolutivo depende de uma dosagem correta, por assim dizer, entre meios sistêmicos, próprios das relações de produção (ainda que estas não se confundam com tais meios em todos os casos e nem se desenvolvam apenas com base em seu fomento, naturalmente) e necessidades sociais, entre imperativos técnicos da estrutura administrativo-produtiva e conteúdos normativos do mundo da vida. A dosagem correta significaria que é preciso promover concomitantemente um e outro, ou seja, de que o desenvolvimento econômico não deve apenas ser percebido a partir da produção da riqueza e da normalidade dos padrões de acumulação, mas também - e fundamentalmente - a partir de sua distribuição, 
do grau de generalização do bem-estar individual e social que essa mesma produção da riqueza potencializa.

Isso alerta as posições de esquerda a não descurarem de uma postura teórico-política caracterizada pela ênfase em um modelo de Estado de bem-estar social renovado, reafirmado ante as posições neoconservadoras e marcado pela regulação econômica e pela realização de políticas de integração material. A esquerda não entrou fortalecida neste início de século XXI por acaso, e sim porque esse modelo de Estado de bem-estar social, calcado no controle da economia, na democracia política e na justiça distributiva, mostrou-se um eficiente instrumento político no que tange à orientação da evolução social, em particular em relação ao sucesso da pacificação social levada a efeito exatamente com base em um crescimento econômico que, ao mesmo tempo em que era promovido, também era, em grande parte, canalizado politicamente para a realização de políticas sociais inclusivas, minimizando os impactos das lutas de classe e da exploração do trabalho. Essa programática permitiu que a reconstrução das sociedades desenvolvidas após a Segunda Guerra Mundial fosse muito bem-sucedida e que os conflitos entre capital e trabalho fossem politicamente intermediados de um modo que beneficiasse ambos os lados.

Essa receita, de todo modo, é hoje posta novamente à ordem do dia, na medida em que a recessão econômica impacta de maneira arrasadora aos grupos mais vulneráveis da sociedade, que são submetidos a uma situação permanente de desemprego e de instabilidade no que diz respeito a um nível mínimo de vida. Ora, a austeridade das políticas estatais e a sobrevalorização do poder do setor financeiro (que enquadra a política social e econômica dos Estados nacionais) representam o endossamento de um laissez-faire que transforma o Estado pura e simplesmente em instrumento de promoção, de legitimação e de reprodução das relações de produção, concebidas enquanto autorreferenciais e como possuindo primazia em relação aos interesses generalizáveis e aos argumentos normativos advenientes do social, já que ele retira-se de qualquer postura diretiva mais substancial em relação aos mercados, correlatamente ao seu afastamento das considerações normativas advenientes da sociedade civil, do mundo da vida daqueles que são atingidos mais duramente pelas crises sistêmicas. Nesse sentido, percebe-se que o Estado de bem-estar social tem por função exatamente proteger e fomentar o mundo da vida frente ao poder sistêmico dos imperativos econômicos e das lutas de classe ali desenroladas - papel esse que não pode ser abandonado. Neste início do século XXI, consolidou-se claramente um papel positivo no que diz respeito ao Estado e à política, que deve ser assumido em sua efetividade pela esquerda, em particular diante da atual crise socioeconômica. A ideia de uma política diretiva da evolução social adquire atualidade e centralidade na resolução da crise socioeconômica hodierna, conforme penso, devido ao fato de que tal crise exige diretamente uma resolução que, como deveria 
ser o caso da política democrática, seja tomada com base em considerações normativas, muito mais do que considerações técnicas.

Isso significa que a afirmação política de interesses generalizáveis (ou universalizáveis) é o primeiro e fundamental quesito para pensar-se qualquer saída para a crise socioeconômica, haja vista que se trata de um conflito entre o processo de acumulação, propugnado pelas posições neoconservadoras como fim em si mesmo, e as necessidades sociais de indivíduos e grupos que, para serem alcançadas, dependem do enquadramento do econômico por meios políticos. A política passa para primeiro plano enquanto instância diretiva da evolução social e dessa crise socioeconômica devido ao fato de que é sensível às necessidades sociais, por estar calcada em normatividade, diferentemente do laissez-faire econômico. Assim, a afirmação de uma sociedade organizada democraticamente carrega concomitantemente a ênfase em uma política forte, diretiva da evolução social, realizada em termos de Estado - de um poder estatal ligado a focos de democracia de base, sensível às necessidades sociais e em parceria com iniciativas cidadãs e grupos sociais os mais diversos.

Por outro lado, é exatamente no cerne do Estado e enquanto luta política que a crise socioeconômica hodierna pode ser percebida em seu sentido verdadeiramente político, como conflito de classe. É que, interessantemente, a resolução para a crise, a partir da contraposição entre esquerda e direita, entre social-democracia e neoconservadorismo, tem como base a luta sobre o sentido, as funções e os fins desse mesmo Estado de bem-estar social. As origens da crise, suas consequências e as possíveis soluções a serem buscadas, portanto, estão relacionadas com a própria compreensão teórico-política acerca da relação entre Estado de bem-estar social, economia e democracia, e é por isso que, como disse várias vezes ao longo do texto, argumentos e posições políticas da segunda metade do século XX foram retomados. Para nós, conterrâneos dessa situação socioeconômica precária, a disputa teórico-política entre social-democracia e neoliberalismo tornou-se rediviva, e vai definir muito da dinâmica das lutas teórico-políticas em torno à compreensão da crise socioeconômica. Entretanto, como acredito, essa situação de crise está favorecendo as posições de esquerda, em particular aquelas calcadas na afirmação do Estado de bem-estar social, na correlação entre democracia política e justiça social, que, depois de um longo período de hegemonia neoliberal, revelou-se como uma instituição fundamental para a estabilidade da própria sociedade, consolidando-se enquanto instância política por excelência no que tange à direção do processo de evolução social, congregando funções interventoras e compensatórias que sob hipótese alguma podem ser abandonadas.

O capitalismo enquanto projeto mundial está em crise permanente e grave - e a atual crise socioeconômica tem como novidade o fato de que as nações desenvol- 
vidas são afetadas fortemente por uma situação de recessão econômica, endividamento público e desemprego estrutural galopantes anteriormente mais intensos em sociedades ditas subdesenvolvidas. Note-se, da mesma forma, que as duas forças teórico-políticas aqui salientadas - social-democracia e neoliberalismo - não esgotam o horizonte de alternativas teórico-políticas, mormente aquelas representadas por uma esquerda mais radical que parte exatamente da falência do capitalismo enquanto projeto mundial e da recusa da possibilidade de conciliação entre capital e trabalho nos marcos do Estado de bem-estar social. Dei preferência, no texto, sem ignorar ou minimizar a importância de outras posições teórico-políticas, à social-democracia e ao neoliberalismo, porque a evolução de nossas sociedades atuais e a consolidação do capitalismo tardio enquanto projeto mundial afirmaram diretamente pontos positivos e desafios ligados ao Estado de bem-estar social europeu. Quanto aos pontos positivos, saliente-se as lutas sociais em torno aos direitos individuais, políticos e sociais, que fazem parte da dinâmica de qualquer nação contemporânea e que apontam diretamente para a afirmação de uma política forte, congregada em um Estado forte e ligado à sociedade civil politizada (bem como dependente dela). Saliente-se, ainda, aqui, a busca por mediação entre capital e trabalho, ainda que sempre frágil - grande parte dos compromissos partidário-administrativos atuais giram em torno desse objetivo e buscam realizá-lo. Quanto aos aspectos negativos, pense-se no crescimento da burocracia, do poder e da autonomia dos partidos políticos frente à sociedade civil, que em várias situações solapam o potencial político dessa mesma sociedade civil, de seus movimentos sociais e de suas iniciativas cidadãs. Nesses aspectos, grande parte das sociedades contemporâneas adota modelo similar ao Estado de bem-estar social europeu, em particular no que tange à afirmação de direitos sociais de cidadania, de intervenção e de regulação econômica, da tentativa de mediação dos conflitos entre capital e trabalho, além da permanente participação de uma sociedade civil politizada (movimentos sociais, iniciativas cidadãs, movimentos trabalhistas, grupos culturais diversos) nas decisões sobre os rumos da evolução social. Ora, boa parte da crise socioeconômica hodierna remete-se fundamentalmente, conforme penso, ao fato de que a política partidário-administrativa rendeu-se ao conservadorismo e à sua política de austeridade, afastando-se das vozes das ruas e dos becos, recusando contato mais estreito com movimentos sociais e iniciativas cidadãs. Boa parte da política administrativo-partidária, por conseguinte, capitulou ante interesses sistêmicos da economia capitalista, minando a normatividade adveniente do social. Aqui, a retomada da social-democracia enquanto posição de esquerda calcada em uma política forte, interventora e compensatória, seria o passo decisivo para a superação da crise, na medida em que refrearia o poder dos grandes grupos econômicos, intermediando de modo equitativo capital e trabalho, possibilitando que a esfera econômica fosse sensibilizada a partir dos interesses normativos fundados no social e afirmadores de uma política democrática que leva em conta interesses generalizáveis ou universali- 
záveis. Política forte deveria ser a palavra de ordem de uma esquerda que enfrenta com coragem essa crise socioeconômica atual - e aqui, inclusive, surgiria a possibilidade de readequação do capitalismo enquanto projeto socioeconômico mundial.

Abstract: the paper argues that debate related to resolution of current economic crisis emphasizes again the conflict between social-democracy, which defends the Welfare State in its functions of economic intervention and material integration, and neoliberalism or neo-conservatism, which defends the self-referentiality of economy, and so the economic crisis is caused by alien mech-anisms (political and normative) that violate its self-referential logic. With this, the paper defends that beginning of 21st century is the great moment of left programmatic, founded in the affirmation of Welfare State, based in a wide social consensus, and undermining important principles of economic laissez-faire.

Key-words: economic crisis; social-democracy; neoliberalism; State; directive politics.

\section{Referências}

AbENDROTH, Wolfgang. A história social do movimento trabalhista europeu. Rio de Janeiro: Paz e Terra, 1977.

ANTUNES, Ricardo. Eliminar o desemprego no capitalismo é uma ficção. Cadernos IHU em Formação, Ano 1, n. 5, 2005.

CHESNAIS, François. A mundialização do capital. São Paulo: Xamã, 1996.

FERREIRA, Mauricio. Recalibrar o modelo social europeu: acelerar as reformas, meIhorar a coordenação. In: DELGADO, Mauricio Godinho; PORTO, Lorena Vasconcelos (Orgs.). O Estado de bem-estar social no século XXI. São Paulo: Editora LTr, 2007.

GoRZ, André. A crise e o êxodo da sociedade salarial. Cadernos IHU em Formação, Ano 1, n. 5, 2005.

HABERMAS, Jürgen. Mudança estrutural da esfera pública: investigações quanto a uma categoria da sociedade burguesa. Rio de Janeiro: Tempo Brasileiro, 1984.

—_ Ciência y técnica como "ideologia". 2. ed. Madrid: Editorial Tecnos, 1994.

_. Problemas de legitimación en el capitalismo tardio. Madrid: Ediciones Cátedra, 1999.

. Ensayos políticos. Barcelona: Ediciones Península, 1997.

. Teoría de la acción comunicativa. (T. 2): Crítica de la razón funcionalista. Madrid: Taurus, 2001.

. La necesidad de revisión de la izquierda. Madrid: Editorial Tecnos, 1991. 
_. La constelación posnacional: ensayos políticos. Barcelona: Ediciones Paidós, 2000.

Ay. Europa! - Pequeños escritos políticos. Madrid: Editorial Trotta, 2009.

HARRINGTON, Michael. Socialismo: passado e futuro. In: Hook, Sidney et alii. A social-democracia nos Estados Unidos. Brasília: Instituto Teotônio Vilela, 1999.

HARVEY, David. O neoliberalismo: história e implicações. São Paulo: Edições Loyola, 2008.

HAYEK, Friedrich August von. O caminho da servidão. 4. ed. Rio de Janeiro: Instituto Liberal, 1987.

—. Arrogância fatal: os erros do socialismo. Porto Alegre: Ortiz, 1988.

- Direito, legislação e liberdade: uma nova formulação dos princípios liberais de justiça e de economia política (v. II) - a miragem da justiça social. São Paulo: Visão, 1985.

Hook, Sidney. O sentido moral da social-democracia. In: Hook, Sidney et alii. A social-democracia nos Estados Unidos. Brasília: Instituto Teotônio Vilela, 1999.

KATZ, Michael B. The undeserving poor: from the war on poverty to the war on welfare. New York: Pantheon Books, 1989.

KolAKOWSKI, Leszek. O desafio social-democrata. In: Hook, Sidney et alii. A social-democracia nos Estados Unidos. Brasília: Instituto Teotônio Vilela, 1999.

KRUGMAN, Paul. O regresso da economia da depressão e a crise actual. 2. ed. Lisboa: Editorial Presença, 2009.

KUHNLE, Stein. A globalização e o desenvolvimento das políticas sociais. In: DeLGADO, Mauricio Godinho; PORTO, Lorena Vasconcelos (Orgs.). O Estado de bem-estar social no século XXI. São Paulo: Editora LTr, 2007.

KURZ, Robert. A globalização deve se adaptar às necessidades das pessoas, e não o contrário. Cadernos IHU em Formação, Ano 1, n. 5, 2005.

MACPherson, C. B. La teoría política del individualismo posesivo: de Hobbes a Locke. Barcelona: Editorial Fontanela, 1972.

- Ascensão e queda da justiça econômica e outros ensaios: o papel do Estado, das classes e da propriedade na democracia do século XX. Rio de Janeiro: Paz e Terra, 1991.

MANow, Philip. As vantagens institucionais comparativas dos regimes de Estado de bem-estar social e as novas coalizões na sua reforma. In: DELGADO, Mauricio Godinho; 
PORTO, Lorena Vasconcelos (Orgs.). O Estado de bem-estar social no século XXI. São Paulo: Editora LTr, 2007.

MARX, Karl. Manuscritos econômico-filosóficos. São Paulo: Editora Martin Claret, 2006. MARX, Karl; Engels, Friedrich. A ideologia alemã. São Paulo: Martins Fontes, 2008.

MerRIEN, François Xavier. O novo regime econômico internacional e o futuro dos Estados de bem-estar social. In: DELGADO, Mauricio Godinho; PORTO, Lorena Vasconcelos (Orgs.). O Estado de bem-estar social no século XXI. São Paulo: Editora LTr, 2007.

Rosanvallon, Pierre. A nova questão social: repensando o Estado providência. Brasília: Instituto Teotônio Vilela, 1998.

StreeCK, Wolfgang. As crises do capitalismo democrático. Novos Estudos Cebrap, n. 2, Mar. 2012, p. 35-56. 